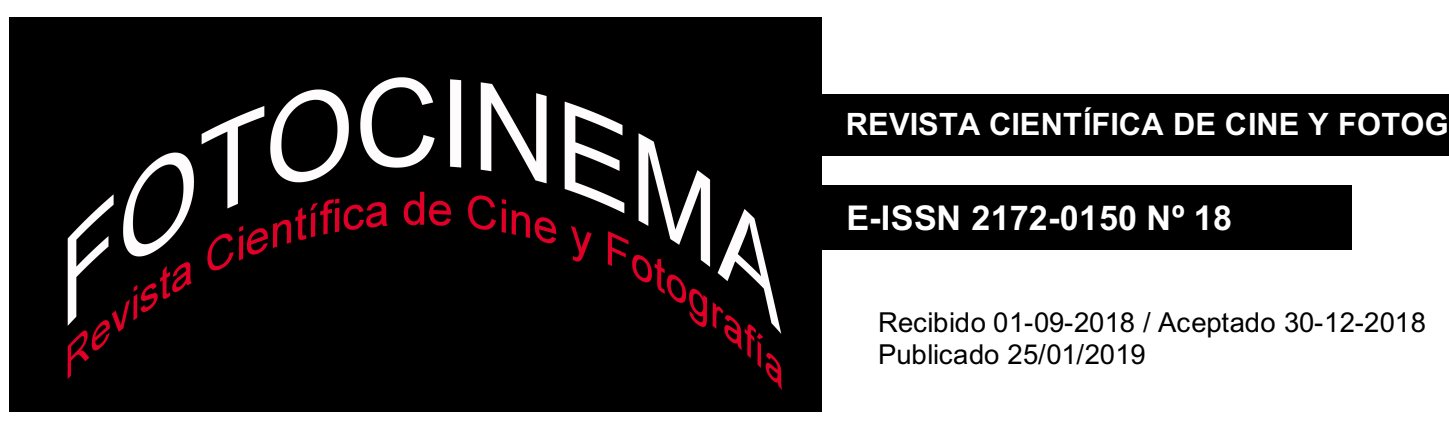

\title{
El devenir de las imágenes en los años de la última dictadura militar argentina: circulación y recepción de las ficciones hermético- metafóricas
}

\section{The evolution of the images in the years of the last argentine military dictatorship: circulation and recepcion of hermetic-metaphorical fictions}

\author{
Ana Laura Lusnich \\ Universidad de Buenos Aires - Consejo Nacional de Investigaciones \\ Científicas y Técnicas, Argentina \\ alusnich@gmail.com
}

\section{Resumen:}

En el transcurso de la última dictadura militar argentina (1976-1983), el cine y los medios audiovisuales en general se transformaron en actores significativos en la transmisión y la aprobación de las políticas del régimen militar. En tanto, un sector no menos amplio mantuvo una posición crítica y reflexiva sobre el accionar de la dictadura. El objetivo de este trabajo es indagar sobre el devenir público de un segmento de la producción cinematográfica realizada en ese período -las ficciones hermético-metafóricas que interpelaban de forma oblicua la realidad política y social del momento-, con el interés de conocer el grado de aceptación por parte de las instituciones públicas de la época, los receptores y los medios periodísticos. El trabajo está enfocado particularmente en cuatro filmes realizados por dos directores disidentes del régimen, que tuvieron éxito de público en salas comerciales y generaron respuestas disímiles en el campo de la opinión pública y los medios periodísticos: La isla (Alejandro Doria, 1979), Los miedos (Alejandro Doria, 1980), Tiempo de revancha (Adolfo Aristarain, 1981) y Últimos días de la víctima (Adolfo Aristarain, 1982).

\begin{abstract}
:
In the course of the last Argentine military dictatorship (1976-1983), the cinema and the audiovisual media in general became significant actors in the transmission and approval of the policies of the military regime. On the other hand, a no less broad sector maintained a critical and reflective position on the actions of the dictatorship. The objective of this work is to investigate the public evolution of a segment of the film production made in that period -the hermetic-metaphorical fictions that obliquely interpellated the political and social reality of the moment-, with the interest of knowing the degree of acceptance on the part of the public institutions of the time, the spectators and the journalistic media. The work is focused on four films in particular made by two dissident directors of the regime, who were successful in commercial cinemas and generated dissimilar responses in the field of public opinion and the media: The Island (Alejandro Doria, 1979), The Fears (Alejandro Doria, 1980), Time of Revenge (Adolfo Aristarain, 1981) and Last Days of the Victim (Adolfo Aristarain, 1982).
\end{abstract}

Palabras clave:

Dictadura argentina; ficciones hermético-metafóricas; circulación; recepción; medios periodísticos.

Keywords:

Argentine dictatorship; Hermetic-metaphorical fictions; Circulation; Reception; Journalistic media. 


\section{Introducción. Modos de expresión y funcionamiento del campo audiovisual en los años de la dictadura militar}

En el curso de la última dictadura militar argentina (1976-1983), las acciones desplegadas por intelectuales y agentes culturales que respondían a sectores políticos y culturales diversos conformaron una trama compleja que lejos de señalar un espacio-tiempo vacío o inerte lo designa marcado por la lucha manifiesta de ideales contrapuestos. ${ }^{1}$ Formando parte del tejido sociocultural las manifestaciones artísticas se transformaron en actores significativos en la transmisión y aceptación de las políticas del régimen militar, en tanto un segmento no menos amplio de ellas halló métodos alternativos para desarrollar y sostener una posición crítica y reflexiva frente al régimen. En lo que respecta a la producción audiovisual, es posible considerar cuatro grandes modos de expresión que abarcaron la actividad de los realizadores y equipos de trabajo en suelo argentino y en el exterior, los que revelaron mayor o menor afinidad con la ideología de la dictadura. ${ }^{2}$

En primer término, se produjeron comunicados, cortos y programas televisivos que estuvieron abocados al anuncio de las acciones y medidas de gobierno y a la construcción del discurso oficial. Esta situación se consolidó a través de la

\footnotetext{
${ }^{1}$ En las últimas décadas, historiadores y estudiosos de la cultura se han dedicado a reconstruir la trama intelectual de la época. Entre ellos, mencionamos: Altamirano, C. (1986). El intelectual en la represión y en la democracia. Punto de Vista, IX (28), 1-4; López Laval, H. (1995). Autoritarismo y cultura, Madrid: Espiral Hispano Americana; De Diego, J. (2003). ¿Quién de nosotros escribirá el Facundo? Intelectuales y escritores en Argentina (1970-1986), La Plata: Al Margen; Álvarez, E. (2006-2007). Los intelectuales del 'Proceso'. Una aproximación a la trama intelectual de la última dictadura militar. Políticas de la Memoria (6-7), 79-85, http://old.cedinci.org/politicas/pm6_7.htm.

2 En el transcurso de este trabajo utilizaremos de forma indistinta los conceptos "dictadura militar", "régimen militar" y "régimen". Con ellos se hará referencia al sistema totalitario de gobierno que, entre otros períodos de la vida institucional de la Argentina, se sucedió entre 1976 y 1983. En estos años, todos los poderes del Estado se concentraron en un pequeño grupo jerárquico de las Fuerzas Armadas, encabezado por una Junta Militar, con respaldo de sectores de la sociedad civil. En lo que respecta a la producción cinematográfica, no será posible hablar de un "cine de régimen" por no haber existido un plan o un proyecto global del gobierno para con el arte cinematográfico. Sí haremos referencia a obras cinematográficas y televisivas de propaganda que, como expresara Pierre Sorlin (2013), nos permiten vislumbrar los sueños y las expectativas de los regímenes autoritarios, y a las relaciones de poder del Estado con la cultura mediante el ejercicio de la censura. De igual manera, tampoco emplearemos el concepto de cine de "contrarégimen", ya que por motivos de censura y persecución política los documentales y ficciones que emprendieron la denuncia directa y explícita contra el régimen militar pudieron concretarse en el exilio, en un conjunto reducido.
} 
intervención y el control absoluto de las emisoras. ${ }^{3}$ En los primeros años de la dictadura la Armada tuvo a su cargo la Secretaría de Información Pública -SIP-, institución que intervenía de manera directa en el diseño de la política cultural nacional y en su comunicación y difusión pública. Estratégicamente, la SIP dirigía y administraba los principales medios de comunicación: el Instituto de Cinematografía, la Dirección General de Radio y Televisión, la Agencia de Noticias TELAM, el Ente de Calificación Cinematográfica y el Comité Federal de Radiodifusión -COMFER- (Rodríguez, 2015). De igual manera, la SIP y el COMFER fueron los organismos encargados de la confección y la difusión de las reglamentaciones y disposiciones del sector, las que, junto con los memorándums y las circulares que funcionaban internamente, los despidos y la persecución a periodistas, conformaban los diferentes niveles de control y censura vigentes en la época (Avellaneda, 1986). En esta estructura, TELAM y la Televisión Pública Argentina -ATC- concentraron la producción de la programación de radio y televisión, en tanto las emisoras cumplían la misión de retransmisión, sin la posibilidad de incorporar modificaciones ni comentarios. Los géneros habituales en la construcción del discurso oficial fueron los comunicados y los micros de corta duración, directamente protagonizados por las autoridades militares que frente a cámara exponían las disposiciones y acciones de gobierno4; los noticiarios, programas diarios que se convirtieron en herramienta de comunicación de las Fuerzas Armadas y en espacio de toma de posición de las mismas, 5 y las coberturas especiales de acontecimientos históricos y deportivos

\footnotetext{
3 En su conjunto, las Fuerzas Armadas se hicieron cargo de los canales de televisión: Canal 7 (denominado ATC a partir de 1978) dependió de la Presidencia de la Nación, Canal 13 de la Armada, Canal 11 de la Fuerza Aérea y Canal 9 del Ejército.

4 El 24 de marzo de 1976 asumieron el poder el general Jorge Rafael Videla, el almirante Emilio Massera y el brigadier Orlando Ramón Agosti. Esta Junta Militar implantó ese mismo día el sistema de comunicados para dar a conocer las medidas que imperarían en el país. El contenido del Comunicado No 1 era el siguiente: "Se comunica a la población que, a partir de la fecha, el país se encuentra bajo el control operacional de la Junta de Comandantes Generales de las FF.AA. Se recomienda a todos los habitantes el estricto acatamiento a las disposiciones y directivas que emanen de autoridad militar, de seguridad o policial, así como extremar el cuidado en evitar acciones y actitudes individuales o de grupo que puedan exigir la intervención drástica del personal en operaciones".

5 Uno de los más populares, creado en 1979 y que se emitía por ATC, fue el noticiero 60 Minutos conducido por el periodista José Gómez Fuentes. El programa, entre otros hechos, fue el promotor de la convocatoria a Plaza de Mayo efectuada el 9 de abril de 1982 en el momento en que tenía lugar la Guerra de Malvinas. Otros periodistas incondicionales al régimen fueron Horacio Larrosa, creador de 60 Minutos, Oscar Casco y José María Muñoz.
} 
(el Mundial de fútbol 1978 y la Guerra de Malvinas, en especial), ${ }^{6}$ a través de las cuales se exaltaba el espíritu patriótico no sin manipular a las audiencias y faltar a la verdad de los hechos.7 Como ha expuesto Silvia Romano (2007), los periodistas y trabajadores del sector no disponían de canales que permitieran la transgresión a las pautas fijadas por el Estado. La abolición de los derechos de los trabajadores -de reunión, de huelga y de funcionamiento de las asociaciones profesionales-, el estudio de los legajos personales, los sumarios, los despidos, las cesantías, la persecución y el asesinato premeditado, actuaron como mecanismos y procedimientos para el control y el disciplinamiento laboral y social, siendo consecuencias inmediatas de los mismos la autocensura, la constricción de los comportamientos y la obediencia a las normativas instituidas. ${ }^{8}$

En segunda instancia, con apoyo privado y/o estatal, se realizaron una amplia serie de filmes ficcionales que aceptaron y difundieron los núcleos ideológicos centrales del régimen militar. En líneas generales, se trató de filmes genéricos que por su estatuto textual alentaron los valores de la unión familiar y el culto a la religión católica -en esta dirección procedieron numerosas comedias y melodramas familiares como han sido los casos de El Tío Disparate (Ramón Ortega, 1977) y Qué linda es mi familia (Ramón Ortega, 1980)-9, en tanto otros filmes naturalizaban la violencia y los actos de persecución y tortura. Para ello, fue común en estos años la realización de filmes de acción protagonizados por agentes parapoliciales que contaron con gran aceptación por parte del público.

\footnotetext{
${ }^{6}$ Documentos de época señalan que la cobertura del Mundial de fútbol de 1978 incrementó considerablemente la audiencia televisiva. Sobre la cobertura del conflicto bélico en las Islas Malvinas, se produjeron varios hitos históricos. Entre ellos, el 2 de abril de 1982, día del desembarco de las fuerzas militares argentinas en las islas, Argentina Televisora Color realizó una transmisión en directo y emitió una entrevista a Nicanor Costa Méndez, ministro de Relaciones Exteriores. Otro récord de audiencia en torno a este conflicto se produjo durante la emisión del programa especial para recaudar fondos para la causa de Malvinas titulado 24 horas por Malvinas, que condujeron Lidia Satragno "Pinky" y Cacho Fontana el 9 de mayo de 1982.

7 En relación con esta serie de producciones, existieron asimismo dos filmes de propaganda que exaltaban el accionar de las fuerzas armadas: Ganamos la paz (Francisco Javier Mendoza, 1977), documental de montaje que revisaba parte de la historia argentina y destacaba el rol cumplido por los militares en la organización y la pacificación nacional; y "Estoy herido", ataque! (Federico Alegre, 1977), ficción que giraba en torno al proceder de las Fuerzas Armadas en su lucha contra la guerrilla en la provincia de Tucumán en 1975.

8 En un panorama tan hostil, pocas voces lograron el cometido de alzarse contra la dictadura. Entre ellos, el periodista Eduardo Aliverti condujo por radio Continental Anticipos, uno de los pocos programas de oposición. Ya en los primeros años de la democracia restituida en 1983, continuaría su labor en el programa radial Sin anestesia.

9 Enmarcadas en el género de la comedia, ambas se sostienen en situaciones de enredo y confusión que se resuelven a favor de la unidad familiar y la tolerancia de las diferencias generacionales.
} 
En estos el sistema de contraposición de dos bandos opuestos funcionaba como evocación para la justificación de los relatos y del discurso del poder; de esta manera: "el régimen cinematográfico en que se alojan las fuerzas antagónicas impulsa la idea de 'alguien que viene de afuera' a quedarse con 'lo ajeno' y 'otro que lo repele y procura recuperar aquello que peligra"' (Wolf, 1992, p. 275)..$^{10}$ Por otra parte, es posible comprobar a través de estas realizaciones la comunión ideológica trazada entre las producciones cinematográficas y las televisivas, situación que quedó demostrada con el estreno de La fiesta de todos (Sergio Renán, 1979), presentado a un año del festejo de la copa mundial de fútbol que dio por ganadores a los argentinos. En su factura textual el filme conjugaba una línea de intriga ficcional con asiento en el género de la comedia familiar, con material de archivo televisivo del evento deportivo. Mediante la técnica del remontaje de los fragmentos documentales (Weinritcher, 2005), se creaba una unidad de sentido que enfatizaba la alegría popular frente a la victoria deportiva tanto como la comunión entre los ciudadanos y los altos mandos militares que presidían y alentaban los encuentros futbolísticos.

Frente a las dos vertientes mencionadas, una tercera modalidad estuvo constituida por las ficciones cinematográficas de corte hermético-metafórico ${ }^{11}$ que ofrecían resistencia al régimen y propiciaban la crítica transversal al contexto político y social (Lusnich, 2016).12 Respecto de esta tendencia, en la cual estará enfocado este artículo y en torno a la cual he realizado una serie de

\footnotetext{
${ }^{10}$ La serie de filmes de superagentes es realmente extensa y recorre todo el período. Entre otros, mencionamos los siguientes títulos: La aventura explosiva (Orestes A. Trucco, 1976), Los superagentes biónicos (Adrián Quiroga -seudónimo de Mario Sábato-, 1977), La aventura de los paraguas asesinos (Carlos Galettini, 1979), Comandos azules (Emilio Vieyra, 1980) y Comandos azules en acción (Emilio Vieyra, 1980).

${ }^{11}$ La denominación de la tendencia se relaciona con las propuestas realizadas para el cine brasileño de los años 50 y 60 por Ismail Xavier, quien establece la denominación "Historical Allegories" (Xavier, 1999).

${ }^{12}$ El corpus fílmico de la tendencia está integrado por los siguientes filmes: Piedra libre (Leopoldo Torre Nilsson, 1976), No toquen a la nena (Juan José Jusid, 1976), ¿Qué es el otoño? (David J. Kohon, 1977), Crecer de golpe (Sergio Renán, 1977), La parte del león (Adolfo Aristarain, 1978), Proceso a la infamia (Alejandro Doria, 1978), Contragolpe (Alejandro Doria, 1979), La isla (Alejandro Doria, 1979), El poder de las tinieblas (Mario Sábato, 1979), La nona (Héctor Olivera, 1979), El infierno tan temido (Raúl de la Torre, 1980), Los miedos (Alejandro Doria, 1980), Tiempo de revancha (Adolfo Aristarain 1981), El hombre del subsuelo (Nicolás Sarquís, 1981), Los pasajeros del jardín (Alejandro Doria, 1982), El agujero en la pared (David J. Kohon, 1982), Últimos días de la víctima (Adolfo Aristarain, 1982), Volver (David Lipszyc, 1982), El grito de Celina (Mario David, 1983), Los enemigos (Eduardo Calcagno, 1983), El poder de la censura (Emilio Vieyra, 1983), Hombres por hombres (en los subterráneos hacia la libertad) (Roberto Jorge Berardi, 1983), Testigos en cadena (Fernando Spiner, 1983).
} 
aproximaciones previas a sus características textuales y sus variantes internas, es de interés mencionar que los filmes que la integran contaron con financiamiento privado y/o estatal, estreno en salas comerciales de primera y segunda línea y un respaldo considerable por parte de los espectadores y la crítica especializada. ${ }^{13}$ Por su críptica factura textual que entablaba relaciones indirectas con los sucesos históricos del momento, si bien algunos de los filmes de la tendencia enfrentaron situaciones de censura e interferencias en la etapa de calificación y exhibición, en su conjunto, por ignorancia o imposibilidad, no fueron combatidos de forma sistemática. Sobre esta situación es plausible interpretar que la adhesión de los filmes a una textualidad que evade el realismo mimético y que emplea la metáfora y la metonimia en el nivel de la diégesis, haya sido un factor determinante en el desvío de la atención de los censores. En líneas generales, estos estaban abocados a reprimir manifestaciones sexuales explícitas (desnudos y escenas de sexo) y situaciones en las que la disidencia política se realizaba de manera directa y combativa. ${ }^{14}$

Finalmente, una cuarta forma de expresión en el campo del audiovisual estuvo compuesta por los documentales realizados en el exilio político por colectivos cinematográficos y directores perseguidos por el régimen militar. Sobre este conjunto, Javier Campo $(2015 ; 2017)$ ha evaluado que los documentales del exilio establecieron al menos tres tipos de narrativas que acompañaron los sucesos del país ofreciendo puntos de vista disidentes, en tanto asimismo obraron como un instrumento para la difusión en el exterior de las violaciones a los derechos

\footnotetext{
${ }^{13}$ Lusnich, A. L. (2011). Opacidad, metáfora, alegoría: nuevas estrategias discursivas y marcas de la ideología imperante en el cine ficcional del período 1976-1983. En A. L. Lusnich \& P. Piedras (Eds.), Una historia del cine político y social en Argentina. Formas, estilos y registros, Vol. II (467-485). Buenos Aires: Nueva Librería; Lusnich, A. L. (2014). Las ficciones alegóricometafóricas realizadas en Argentina y Chile entre 1973 y 1990. En M. Villarroel (Coord.), Travesías por el cine chileno y latinoamericano (187-196). Santiago de Chile: Centro Cultural La moneda-Cineteca de Chile; Lusnich, A. L. (2016). Formas del disciplinamiento social en las ficciones alegóricas y metafóricas realizadas en épocas de la dictadura y la postdictadura en Argentina. IdeAs. Idées d'Amérique (7), 1-17, http://journals.openedition.org/ideas/1528; DOI: $10.4000 /$ ideas.1528.

14 Del conjunto mencionado, Piedra libre tuvo calificación de exhibición, pero fue levantado de circulación un día antes del estreno, programado para el 15 de abril de 1976. Mediante un litigio con la justicia fue finalmente estrenada en septiembre de 1978 pero retirándosele los beneficios económicos estatales; No toquen a la nena fue objetado por incluir a varios actores sospechados por la dictadura; El agujero en la pared incluía en su final el suicidio del protagonista, lo que motivó muchas intervenciones del Ente de Calificación a la hora de otorgarle el permiso de exhibición; de Últimos días de la víctima se cortaron varias escenas eróticas; El grito de Celina, filmada en 1976, pudo ser estrenar recién en 1983 con el retorno de la democracia.
} 
humanos. Estas narrativas incluyeron la resistencia activa, protagonizada por líderes políticos y activistas que alentaban a la lucha desde un exilio no declarado (Resistir, Jorge Cedrón, 1978, convoca a Mario Firmenich, líder de la organización guerrillera Montoneros; Persistir es vencer, Cine de la Base, 1978, se sostiene en entrevistas hechas a Luis Mattini, secretario general del Partido Revolucionario de los Trabajadores, y a Gorriarán Merlo, miembro del buró político del PRT y comandante del Ejército Revolucionario del Pueblo); la reflexión sobre la problemática del exilio y el desarraigo por motivos políticos (Tango, Jorge Cedrón, 1979, y Reflexiones de un salvaje, Gerardo Vallejo, 1978, se aproximaron al tema del exilio mediante la música de tango y la reconstrucción de la historia de las migraciones y exilios familiares, respectivamente) y, en tercer lugar, la denuncia de la violación de los derechos humanos. En este tercer conjunto, el documental de Humberto Ríos Esta voz... entre muchas (1979) se destacó por incorporar de forma temprana los testimonios de Laura Bonaparte fundadora de Madres de Plaza de Mayo-, Carlos González Gartland -abogado de presos políticos- y Raúl Fonseca -preso político y padre de dos jóvenes asesinados por las fuerzas militares-. 15

La férrea vigilancia y el control que atravesó el sector de la radio y la televisión en los años de la dictadura, tuvo su correlato en el campo del cine en el accionar de una estructura tripartita que abarcó la actividad de la Secretaría de Información Pública, encargada de definir la política cinematográfica; el Instituto Nacional de Cinematografía, con la función de otorgar o denegar créditos y subsidios, y el Ente de Calificación Cinematográfica, que decidía el permiso o la prohibición de exhibición. En mayo de 1976, con la firma del capitán de fragata Carlos Corti, la Secretaría de Información Pública presentó a la sociedad un comunicado que contenía las pautas que regirían el financiamiento y la calificación de las películas: -las que exaltaran al hombre en su lucha eterna en la defensa de los valores morales, patrióticos, la justicia y la religión tendrían ayuda en su realización, estreno público y difusión internacional; -aquellas que propiciaran el

\footnotetext{
15 En los años de la dictadura, por las condiciones señaladas, fue prácticamente imposible realizar documentales críticos o destinados a la denuncia en suelo argentino. Una de las pocas excepciones la constituyó el grupo Cine Testimonio, formado en los primeros años de los '8o por Tristán Bauer, Alberto Giudici, Silvia Chanvillard, Laura Búa, Víctor Benítez y Marcelo Céspedes. La obra inaugural del colectivo, Los totos (1982), narraba la vida cotidiana de los niños en las villas miseria incluyendo testimonios y una alta cuota de observación de la realidad.
} 
mero entretenimiento y nuevos enfoques artísticos no transitados serían apoyadas y estrenadas con reservas; -en tanto en una tercera categoría, sin apoyo financiero y con prohibición de estreno, parcial o total, temporaria o permanente, se incluían las producciones que carecían de valor artístico o de entretenimiento y las que atentaban con los propósitos de reintegrar y revitalizar la comunidad. En el terreno de la censura propiamente dicha, bajo la dirección del crítico de espectáculos Miguel Paulino Tato entre 1976 y 1978, y por un equipo encabezado por el abogado Alberto León a posteriori, el Ente de Calificación Cinematográfica articulaba su tarea a partir de estrategias que tendían a la normalización de los filmes de acuerdo con las reglas estéticas, morales y religiosas vigentes y, simultáneamente, a sofocar cualquier tipo de disidencia ideológica por parte de los directores. ${ }^{16}$ De este modo, convivieron la lectura previa de los guiones, la supresión y el corte de escenas una vez presentado el filme, la demora en la calificación y la eliminación completa de la película. De igual manera, el organismo elaboró listas de cineastas, actores y técnicos vetados y prohibidos, muchos de los cuales fueron perseguidos de forma violenta, amenazados de muerte e incluso asesinados.

\section{Vida pública de los filmes: circunstancias $y$ factores que intervinieron en los estrenos}

La reseña esbozada de la producción y del funcionamiento institucional del campo audiovisual en los años de la dictadura pone de manifiesto la compleja situación que se vivía en Argentina en términos laborales y de expresión. En un clima de vigilancia y control extremos para un amplio sector de realizadores, actores, técnicos y periodistas, surge la pregunta sobre el devenir de las imágenes y sonidos que obraron en disidencia al régimen vulnerando las disposiciones vigentes y la censura. Con el propósito de indagar acerca de estas problemáticas, las reflexiones estarán centradas en el tercer bloque de producciones mencionadas previamente, las ficciones alegórico-metafóricas, a fines de encontrar respuestas a dos interrogantes en particular: 1) ¿cuáles fueron las circunstancias y los mecanismos a partir de los cuales los filmes obtuvieron

\footnotetext{
16 Bajo el gobierno de Onganía, a fines de 1968, se sancionó la ley 18.019. Esta ley creó el Ente de Calificación Cinematográfica y definió mediante un marco legal cuáles eran las razones por las que una película podía ser censurada y/o prohibida.
} 
estreno en salas comerciales y visibilidad pública?, y 2) ¿cómo intervinieron la crítica especializada y los medios periodísticos en general en la interpretación, la promoción y la difusión de los filmes? En el desarrollo de estos temas voy a referirme particularmente a cuatro de los filmes de la tendencia, que en función de sus fechas de estreno recorren el período histórico analizado y permiten estudiar de forma concreta las motivaciones, relaciones y tensiones existentes en el campo cultural y en la sociedad argentina en general: La isla (Alejandro Doria, 1979), Los miedos (Alejandro Doria, 1980), Tiempo de revancha (Adolfo Aristarain, 1981) y Últimos días de la víctima (Adolfo Aristarain, 1982).17

De acuerdo con el volumen de los filmes involucrados en esta tendencia cinematográfica y la regularidad manifiesta en sus instancias de producción y estreno, es posible comprobar que se trató de una línea expresiva que ocupó un lugar destacado en el mapa audiovisual de la época (Lusnich, 2015). De los 200 largometrajes nacionales estrenados entre 1976 y $1983,{ }^{18}$ al menos un doce por ciento se corresponde total o parcialmente con la textualidad plasmada por las ficciones hermético-metafóricas. En lo que respecta a la actitud de los realizadores, los recién mencionados -Alejandro Doria y Adolfo Aristarainfilmearon cuatro y cinco películas cada uno en el período, continuidad laboral que más allá de asegurar el desempeño en el oficio que les era propio exponía la decisión de forjar a través de las realizaciones cinematográficas una actitud intelectual crítica frente a los acontecimientos históricos que les tocaba vivir. ${ }^{19}$

En lo que atañe a los planteles actorales que intervinieron en los filmes de esta tendencia es de interés recabar en el hecho de que varios de los intérpretes fueron

\footnotetext{
${ }_{17}$ La isla tuvo estreno el 9 de agosto de 1979 en la sala Cinema I; Los miedos fue presentada el 15 de agosto de 1980 en el Gaumont y Cinema I; Tiempo de revancha fue exhibida desde el 30 de julio de 1981 en el Ambassador y en otras salas céntricas y barriales; Últimos días de la víctima tuvo estreno en los cines Ocean y Gaumont el 8 de abril de 1982.

18 No existe un acuerdo certero sobre los estrenos en el período. El número de 200 filmes lo aportan Judith Gociol y Hernán Invernizzi (2006). Los listados provistos por la biblioteca de la Escuela Nacional de Experimentación y Realización Cinematográfica dependiente del Instituto Nacional de Cine y Artes Audiovisuales de Argentina estipulan 197 títulos.

${ }^{19}$ Alejandro Doria filmó en estos años de dictadura cuatro películas. A las ya mencionadas en este trabajo, La isla y Los miedos, se sumaron Contragolpe (1979) y Los pasajeros del jardín (1982). En todas ellas el contexto social y político de la dictadura intervenía de forma directa en el desempeño y el destino de los personajes. Adolfo Aristarain, por su parte, filmó cinco filmes. En lo que respecta a su raíz genérica, estos oscilaron entre las comedias pasatistas (La playa del amor, 1980; La discoteca del amor, 1980) y los filmes policiales y testimoniales (La parte del león, 1978; Tiempo de revancha y Últimos días de la víctima). En todos ellos, aún en las comedias, el subtexto se componía del entramado de terror reinante en la época. En tanto, otros directores que adhirieron a la tendencia analizada realizaron entre dos o tres filmes en el período.
} 
sospechados o perseguidos por el gobierno militar. De hecho, al menos cuatro de ellos, siendo estos los más requeridos por los realizadores y por el público (Alfredo Alcón, Héctor Alterio, Federico Luppi y Marilina Ross), formaron parte de las listas negras confeccionadas por autoridades del gobierno militar que incluían a intelectuales, periodistas, artistas y comunicadores que revestían mayor nivel de peligrosidad por -supuestamente- poseer antecedentes ideológicos marxistas, y para quienes existían las directivas de no ser empleados ni promovidos. ${ }^{20} \mathrm{El}$ lugar central que ocupaban estos actores en el campo televisivo, teatral y cinematográfico en la época así como la credibilidad forjada por estas figuras en la opinión pública, fueron dos razones que sin embargo primaron en la contratación de los intérpretes, esquivando y dejando de lado los productores y realizadores las directrices de las autoridades del gobierno militar. De igual manera, es posible comprender que quienes integraron los equipos de trabajo de estos filmes -junto con los realizadores y actores habría que incluir a los guionistas y productores que sostenidamente apoyaron estas películas-21 formaban parte de un colectivo cultural amplio que defendía la libertad de expresión conectándose con los sectores afines de la sociedad a través de sus producciones artísticas e incluso de sus intervenciones públicas. Como ejemplo emblemático, articulando uno de los idearios respaldados en la época por este sector progresista, Alfredo Alcón, sospechado por las autoridades militares, luego de pasar unos cuantos años alejado de la actividad, tuvo la capacidad de realizar declaraciones en las que reflexionaba sobre la censura y sus efectos en los individuos. Entre estas, en diciembre de 1981 declaraba al diario La Prensa:

La censura es la necesidad de que no haya contradicción, de que todo sea parejo (...) En el fondo, la censura ignora al hombre (...) Llámalo como quieras. Pero algo le debe pasar a ese tipo que no habla (...) Ese tipo que se va, que se calla, que no

${ }^{20}$ Las autoridades militares organizaron estas listas en cuatro categorías que clasificaban a las personas involucradas de acuerdo con su grado de adhesión a la ideología marxista. Asimismo, se indicaban de forma clara las instrucciones relativas al tratamiento laboral y al seguimiento de las mismas por parte de las fuerzas militares. Un listado completo de los sospechados puede obtenerse en el siguiente sitio: http://www.mindef.gov.ar/archivosAbiertos/centroDeDocumentos.php?documentos=edificioC ondor.

${ }^{21}$ Habría que incluir en este conjunto a varios de los guionistas que eran conocidos por su compromiso político y la defensa de la libertad de expresión (Aída Bortnik, José Pablo Feinmann, entre otros) y a los productores que sostenidamente apoyaron estas películas (entre ellos Lita Stantic, que trabajó en varios de los proyectos de Alejandro Doria, y la empresa Aries, que cofinanció y apoyó la realización de comedias de diferentes vertientes y a varios de los filmes de la tendencia estudiada). 
arma escándalo, que ni siquiera sabe dónde o a quien quejarse, vive un silencio terrible. ${ }^{22}$

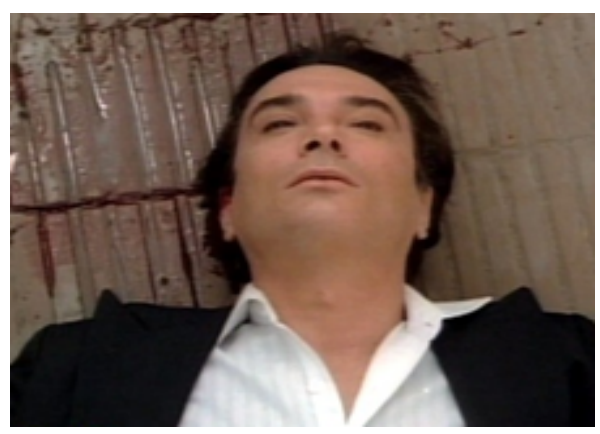

F1. Bruno Sánchez (interpretado por Alfredo Alcón), yace muerto en el final de Un agujero en la pared, luego de arrojarse desde las alturas de un edificio

Más allá de este tejido humano y artístico suficientemente amplio que funcionó como matriz y como soporte tangible del desenvolvimiento histórico de la tendencia analizada, un segundo aspecto que intervino en la vida pública de los filmes residió en el hecho de que la mayoría tuvo estreno en salas comerciales de primera y segunda línea y una respuesta suficientemente satisfactoria de los espectadores. Con un sentido netamente empresarial concentrado en la explotación del capital artístico y simbólico de los intérpretes y realizadores, la mayoría de los dueños de las salas involucradas en los estrenos aceptaban las condiciones existentes, aún a sabiendas de posibles represalias o enfrentamientos con el poder militar. 23 En este terreno, los filmes de Alejandro Doria atravesaron algunos inconvenientes con la censura; sin embargo, los exhibidores no dudaron en elegirlos. En 1975 su filme Proceso a la infamia había sido inicialmente prohibido por el Ente de Calificación por considerarlo pornográfico y con abundancia de violencia -este desarrollaba el tema de la trata de personas y la prostitución juvenil-, obteniendo su certificado de calificación, con los cortes de algunas escenas en 1978. En tanto, las tres realizaciones posteriores del mismo director, Contragolpe, La isla y Los miedos, accedieron a la exhibición luego de una elección medianamente consensuada de los intérpretes, la que se sostenía en las necesidades expresivas que requerían las historias tanto como en las

22 "Declaraciones de Alcón”, La Prensa, 10 de diciembre de 1981.

${ }^{23}$ No todos corrieron similar suerte. El agujero en la pared, de David José Kohon, tuvo un destino incierto. Si bien el director peleó cada escena que el Ente de Calificación quería cortar especialmente no era bien visto el final, en el que el personaje interpretado por Alfredo Alcón se suicidaba-, el exhibidor comprometido en el estreno no quiso darle sala. Finalmente fue estrenado en 1982 luego de innumerables tratativas. 
limitaciones impuestas en su actividad a un segmento de la comunidad artística. Los tres fueron exhibidos en un lapso muy breve de tiempo (1979 los dos primeros, 1980 el tercero) y de ellos La isla fue un resonante éxito de. Por su parte, Tiempo de revancha de Aristarain, presentada el 30 de julio de 1981 simultáneamente en los cines Ambassador, Callao y Gran Norte, entre otros barriales, es otro caso testigo de las tensiones existentes en la sociedad de la época, incluso de las desinteligencias que se habían creado para esa fecha al interior de las fuerzas militares. ${ }^{24} \mathrm{El}$ guion y el filme no tuvieron cortes, el filme obtuvo subsidio especial para su realización y la distribuidora Aries, entonces comandada por quien había oficiado de productor, Héctor Olivera, la colocó rápidamente en el mercado. A partir de entonces, el filme protagonizó una serie de situaciones contrapuestas que ponen en evidencia la puja vigente entre facciones de poder que perseguían distintos intereses. Aristarain relató en una entrevista:

La junta de censura la vio y felicitó a Olivera (...) Les encantó. Luego alguien la vio mejor y armó un buen despelote tratando a los del Instituto Nacional de Cinematografía de pelotudos por haberla apoyado. Por suerte Tiempo de revancha fue un éxito desde el jueves en que se estrenó. El sábado hubo una amenaza de bomba en el Ambassador y hubo que desalojarlo. Hubo llamadas a mi casa y a Olivera. Alfredo Serra, en Somos, sacó un editorial denunciándonos, diciendo que éramos anarquistas (...). Hubo otras protestas, pero no podían hacer nada: nos protegió el

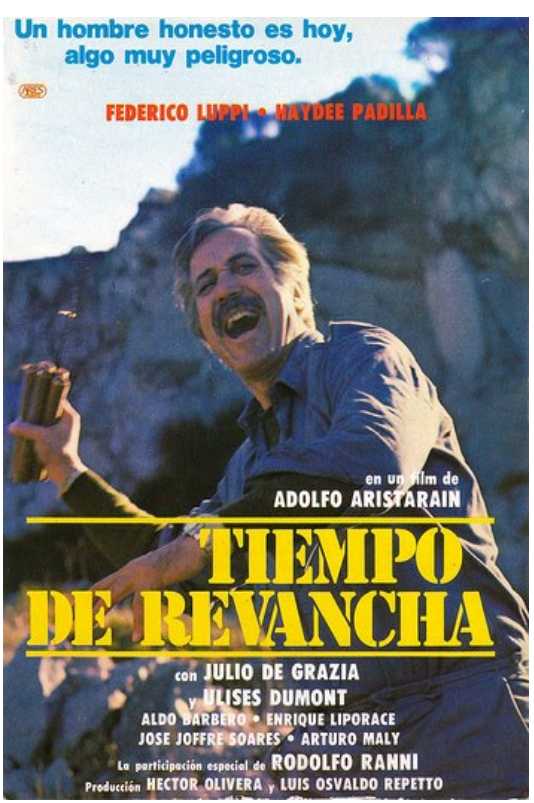
gran éxito". 25

F2. Afiche publicitario de Tiempo de revancha, en el que se destaca la figura de Federico Luppi, acto-faro en la época

\footnotetext{
24 Para esta fecha, Emilio Eduardo Massera, perteneciente a la Armada Argentina, tenía el proyecto de organizar un partido para insertarse en la vida política del país y prolongar por otras vías el programa de gobierno de las fuerzas armadas.

25 "Entrevista a Adolfo Aristarain: Escribí Tiempo de revancha como odio por la dictadura", El barrio. Periódico de noticias, 1 de mayo de 2011. http://periodicoelbarrio.com.ar/\%C2\%93escribi-\%C2\%91tiempo-de-revancha\%C2\%92-conodio-por-la-dictadura\%C2\%94/
} 
En lo que concierne al reconocimiento del público a los filmes de la tendencia es posible trazar una serie de razones que, así como se han venido esbozando para el campo de la comercialización, se relacionan en primera instancia con los elencos convocados que generaban gran atracción en los espectadores. Los filmes estimularon esta situación mediante distintas estrategias, abarcando la presencia de los actores-faro del campo nacional del momento, o bien explotando la modalidad de incluir en el entramado de las historias numerosas figuras protagónicas que coexistían en el plano de la ficción. Asimismo, como ha sido el caso de Los miedos y La isla, la amalgama de figuras pertenecientes a diferentes generaciones y estilos interpretativos funcionaba como un estímulo adicional en las expectativas del público. En esta dirección, Los miedos, estrenada el 15 de agosto de 1980 en las salas Cinema I y Gaumont, marcaba el regreso de Tita Merello al cine. Junto con un conglomerado extenso de jóvenes actores -Soledad Silveyra, María Leal, Sandra Mihanovich, Miguel Ángel Solá, entre otros-, la actriz consagrada en la etapa clásica del cine argentino interpretaba en el filme de Doria a una mujer anciana que huía, junto con todo un grupo de personas, del exterminio planificado y puesto en acción por las autoridades ante la amenaza de una epidemia desconocida. Si bien su desempeño en el desarrollo de la historia era parcial ya que luego de las primeras secuencias su personaje se desvinculaba de los restantes, la crítica no dudó en calificarla como una de las "grandes trágicas" de la escena mundial, ya que con su papel articulaba las vivencias de los demás personajes: "los miedos de la vieja son los miedos de todos: el miedo a la vejez, el miedo a la soledad, el miedo a la muerte". ${ }^{26}$ En La isla, por su parte, se integraron al plantel Luisa Vehil y Chela Ruiz, dos actrices de extensa trayectoria cinematográfica y teatral que aportaron registros interpretativos diferentes que oscilaban entre el realismo y el grotesco, respectivamente. Mediante la combinación de ambos registros sus personajes expusieron de forma potente la locura y el desasosiego reinante en el interior de la institución de salud mental en la que se desarrollaban las situaciones dramáticas.

Otros aspectos a tener en cuenta en la aceptación de estas ficciones por parte de los espectadores es el hecho de que, por sus características textuales y los conflictos tratados, atrajeron a un segmento de público que buscaba conectarse

${ }^{26}$ Fernando Maslloréns, “Una trágica de fuerza arrasadora es el principal atractivo de los miedos”, Convicción, 16 de agosto de 1980. 
con su tiempo histórico a través del ámbito de la cultura y las producciones artísticas. De esta manera es posible sostener que los espectadores generaron un estilo de "recepción cómplice", una voluntad receptora que propiciaba la decodificación de la trama alegórica y metafórica inscripta en los filmes y, consecuentemente, el reconocimiento de estos como piezas que ejercían la reflexión y la crítica política. ${ }^{27}$ Este tipo de asociación participativa puede observarse en los mecanismos a partir de los que se publicitaban los filmes, en lo que respecta a los afiches callejeros y/o publicados en medios de tirada popular. Se trataba de piezas de difusión que en su diseño gráfico incluían frases que establecían estrategias comunicativas destinadas a convocar e incluso a interpelar emocionalmente a los espectadores: "Usted también es protagonista de esta historia" (Los miedos), "Usted... está atrapado dentro o fuera de la isla" (La isla), "Un hombre honesto es hoy, algo muy peligroso" (Tiempo de revancha), destacaban los afiches. También es posible comprobar que existían relaciones estrechas entre los anuncios inscriptos en estos paratextos y el orden textual de los filmes anticipándose, aunque de manera tácita, toda una serie de problemáticas que acuciaban a amplios sectores de la ciudanía: el exterminio y el encierro, núcleos tratados en los filmes de Alejandro Doria; la confrontación con el poder económico, la autoflagelación y la actividad de los asesinos a sueldo, presentes en los de Aristarain. En lo que concierne a estas vinculaciones, un ejemplo destacable se presentó en torno a Tiempo de revancha, en cuanto el destino trágico del "hombre honesto" al cual aludía el afiche de promoción del filme, Pedro Bengoa, enfrentado en la trama ficcional a una empresa multinacional por un litigio laboral, encontraba su representación visual en dos imágenes potentes que quedarían grabadas en la memoria de los espectadores: en una de ellas decide taparse la boca con una cinta adhesiva para no quebrarse y evitar hablar; en la segunda opta por silenciarse para siempre cortándose la lengua con una navaja de afeitar. Como ha señalado Fernando Brenner sobre la repercusión masiva del filme de Aristarain y la empatía generada por su protagonista en los receptores: "Por miles iban a verla, y más de una vez. Llegó a

\footnotetext{
${ }^{27} \mathrm{Al}$ referirse al campo teatral argentino de los años 60 y 70, Osvaldo Pellettieri (1994) reconocía que en el momento en que los regímenes autoritarios se entrometen en el campo intelectual las producciones culturales y artísticas acentúan la crítica oblicua al contexto social. De esta manera, las metáforas transparentes de la realidad permiten una recepción cómplice de un público avisado que participa de la crítica instaurada en los textos.
} 
estar veintidós semanas en cartel, todo un récord. Sucedía que a la gente le contaban una historia que, además de creíble, era cercana” (Brenner, 1993, p. 25). ${ }^{28}$

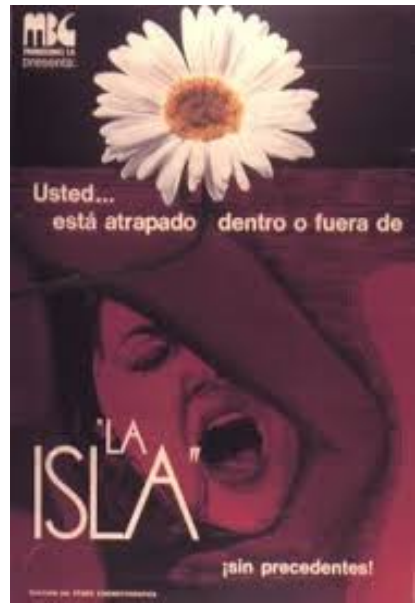

F3. Afiche publicitario de La Isla

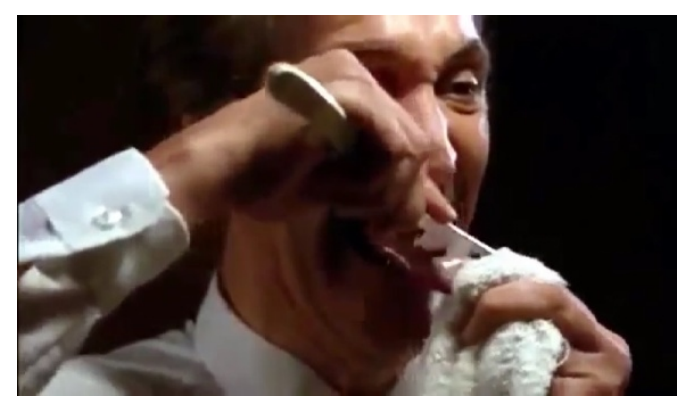

F4. Imagen de Tiempo de revancha, en la que Pedro Bengoa decide cortarse la lengua

\section{El rol de la crítica especializada y de los medios periodísticos en la interpretación, promoción y difusión de los filmes}

Si la actitud de los espectadores conducía a una contralectura de los filmes, a partir de la cual estos se posicionaban como sujetos-actores sociales y culturales activos (Rodríguez, 2015), resulta significativo el rol que asumieron la crítica especializada y los medios periodísticos en general en la divulgación y la interpretación de la línea cinematográfica estudiada. Es necesario mencionar que los filmes tuvieron cobertura de los medios de tirada masiva -diarios y revistas de consumo popular de diferentes orientaciones ideológicas-, así como de aquellos que circulaban subterráneamente y que por su postura en disidencia al régimen integraban -junto con los filmes y otras manifestaciones artísticas- el espacio cultural alternativo de la época (Cerviño, 2012). ${ }^{29} \mathrm{~A}$ su vez, las notas producidas

${ }^{28} \mathrm{Si}$ nos detenemos en Últimos días de la víctima, filme que Aristarain estrena luego de Tiempo de revancha, es posible advertir que su situación es muy diferente. Por un lado, obtuvo menor éxito de público, probablemente debido a que se estrenó el 8 de abril de 1981, en el momento en que se desató la Guerra de Malvinas. Por otro lado, de acuerdo con ideas de Fernando Brenner (1993), a diferencia de Tiempo de revancha, el personaje de Mendizábal, un asesino a sueldo, dificultaba la identificación y la relación emocional con los espectadores.

29 En los años de la dictadura las revistas literarias, culturales y periodísticas alternativas y/o subterráneas ocuparon un lugar destacado en la promoción de artistas y obras que procuraban establecer líneas expresivas novedosas y que no tenían espacios oficiales o convencionales en los que divulgarse. Asimismo, ejercieron como espacio de reunión de intelectuales, artistas y lectores que obraban en disidencia al régimen, ejerciendo la reflexión y el derecho a la libre información. Entre ellas, las que tuvieron gran poder de convocatoria fueron Humor, El porteño y Punto de vista. 
en torno a las películas formaron parte de la campaña de promoción y difusión generada en torno a cada proyecto, efectuando éstas el seguimiento de la preproducción, la selección de los elencos, el rodaje, el estreno y los reconocimientos alcanzados en su circulación nacional e internacional.

Con intereses disímiles y lecturas heterodoxas, este aparato crítico se enfocó en múltiples objetos y aristas asociados a los filmes. En particular produjeron entrevistas a los directores y actores, reseñas de sus trayectorias, comentarios sobre los contenidos y el estilo particular de cada estreno, reportes de los premios y distinciones obtenidas, e incluso balances generales en torno a la producción cinematográfica del período en los que los filmes de la tendencia obtenían comentarios destacados frente a otros. Esta diversidad textual no solo daba una visibilidad peculiar a los filmes tratados, sino que, de igual manera, introducía temas en la agenda de la crítica periodística y fomentaba debates. En esta dirección, es posible comprobar que las notas y comentarios en su mayoría no evadían las circunstancias generadas en derredor de los filmes -prohibiciones, exilios, retornos a la actividad, censura- sino lo contrario, exponían todos estos tópicos exhibiendo con esas determinaciones las tensiones que se trazaban entre el espacio de la cultura y el aparato estatal. Sintomático fue al respecto el apoyo vertido a Héctor Alterio, actor condenado a muerte por la Alianza Anticomunista Argentina -Triple A- en 1974, ausente del país por casi diez años. En sus visitas intermitentes a la Argentina, cumpliendo con algunos pocos compromisos laborales y familiares, fueron innumerables las entrevistas y semblanzas vertidas sobre el actor por los periódicos de tirada masiva: Clarín, el 29 de diciembre de 1979 reseñaba los cuatro primeros años de su vida en el exilio español; La Razón, el 14 de junio de 1980 dejaba constancia de la convocatoria a un nuevo proyecto cinematográfico cursada al actor por Sergio Renán; Clarín, el 7 de enero de 1982 le realizaba una entrevista que ponía en el centro del diálogo las consecuencias y los traumas provocados por el exilio: "Perder mi identidad, perder mi historia, inventarme todo de nuevo, tener que utilizar mi oficio y no mis sentimientos", declaraba Alterio al ser interrogado sobre su situación personal. $3^{30}$ En otro orden reflexivo, en el momento del estreno de Los miedos, Crónica -en su edición del 6

30 "El regreso de un gran actor argentino. Buenos Aires con Alterio", Clarín, 29 de diciembre de 1979; "Después de 6 años regresó al país el conocido actor Héctor Alterio”, La Razón, 14 de junio 1980; Any Ventura, "Héctor Alterio y la esperanza del regreso", Clarín, 7 de enero de 1982. 
de abril de 1980- entrevistaba a una de las intérpretes, María Leal. Además de preguntarle sobre su personaje, una joven embarazada que en el contexto represivo del filme representaba la vida y el futuro, el periodista la enfrentaba al tema de la censura. Pidiendo su opinión sobre este tópico, la actriz manifestaba: "Creo que la censura es una forma de paternalismo y no estoy de acuerdo con ella. Me disgusta que otros opinen por mí". Declaraciones que, a sabiendas de los conflictos que había atravesado Alejandro Doria en el armado del elenco de esa misma película, pudieron estar dirigidas a las autoridades cinematográficas que ejercían como censores e intervenían en el destino de los artistas.

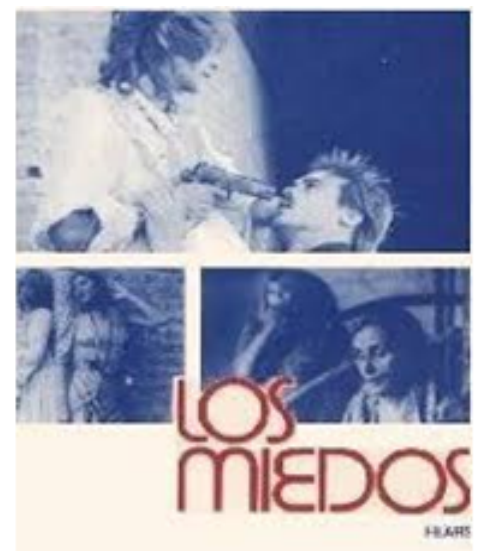

F5. Afiche promocional de Los miedos

También fue significativa la manera en que los medios periodísticos dialogaban entre sí, ya sea fortaleciendo las opiniones creadas sobre los filmes, o bien denunciando las diatribas de otros medios ejercidas sobre algunas de las películas. Como ejemplo, recordando el pedido que el crítico Alfredo Serra dio a conocer públicamente en la revista Somos en el momento del estreno de Tiempo de revancha, a través del cual alertaba a los censores sobre el contenido ideológico del filme, un periodista de Siete Días transcribía parte de esa crítica con el propósito de develar las malas intenciones de su colega. Asimismo, en esa misma nota, recogía las opiniones de otros medios que habían argumentado favorablemente sobre la temática del filme y las aptitudes del realizador. ${ }^{31}$

Si nos enfocamos en la interpretación de las claves textuales de los filmes de la tendencia y en particular de los cuatro elegidos para el análisis, una primera particularidad es que no han operado -salvo pocas excepciones como la mencionada de la revista Somos- la censura ni la deslegitimación. Sin embargo,

31 "Una gran película", Siete Días, 12 de agosto de 1981. 
sí es posible reconocer en los comentarios, críticas y balances realizados al menos tres ejes argumentativos principales, cada uno de los cuales desentrañaba el potencial alegórico y metafórico de los relatos con diferentes alcances.

Uno de ellos propulsaba interpretaciones de corte universalista y/o humanista que vinculaban los personajes y los acontecimientos de los filmes con situaciones que tenían actualidad o vigencia más allá del territorio nacional y del tiempo presente. De esta manera, quienes asumieron este sistema argumentativo eran capaces de identificar núcleos conflictivos tales como la lucha entre el bien y el mal y la defensa de la libertad, sin trazar correspondencias con lo que estaba sucediendo en Argentina en el momento de la realización de los filmes. Sobre los factores que intervinieron en este tipo de interpretaciones la coerción operada en los medios de comunicación y la autocensura se encuentran probablemente en el origen de las mismas. Sin embargo, estas argumentaciones, aunque generalizadoras, se constituyeron en un primer nivel de lectura de las matrices críticas y reflexivas de los filmes, instalando en torno a este corpus las ideas de seriedad y compromiso. En este horizonte se enmarcan numerosas notas realizadas a propósito de los dos filmes estudiados de Alejandro Doria. Sobre $L a$ isla, La opinión del 10 de agosto de 1979 sostuvo que "es esencialmente un estudio de la soledad humana, el de un grupo de marginados mentales y sociales que busca (la mayoría sin lograrlo) el camino de su propia identidad". ${ }^{2}$ Con respecto a Los miedos, La Prensa del 16 de agosto de 1980 acentuaba el carácter impreciso de las locaciones al decir que inmediatamente, luego de unas primeras escenas, la acción "se traslada súbitamente a una ciudad cuya población está siendo diezmada por una peste desconocida. Los siete únicos sobrevivientes (...) iniciarán el éxodo para salvarse, hacia un ignoto lugar del sur de este territorio desconocido". 33 En tanto, La opinión del 21 de agosto retomaba similar descripción y afirmaba:

Una peste ha convertido al mundo en un sitio prácticamente inhabitable, donde los sanos se defienden como pueden de los enfermos (...) Sucede que Doria propone hablar de los miedos ancestrales del hombre, aquellos que determinan

\footnotetext{
32López, Daniel, "Altísimo nivel de calidad en La isla", La opinión, 10 de agosto de 1979.

33“Los miedos”, La Prensa, 16 de agosto de 1980.
} 
problemas fundamentales de su existencia, y, obviamente, ese miedo supremo que ocurre cuando el ser se enfrenta con la nada, con la muerte. 34

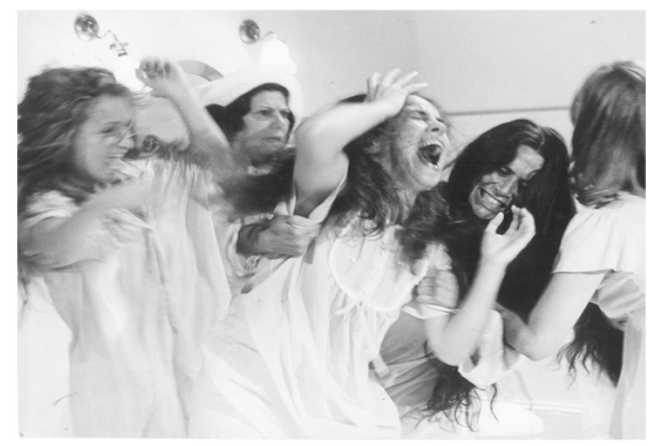

F6. Imagen de La isla, filme en el que un grupo de personas de diferentes estratos sociales y edades conviven en estado de reclusión y aislamiento

Un segundo eje argumentativo lo constituyen los textos y comentarios que localizaron y desentrañaron las operaciones alegóricas y metafóricas de los filmes, trazando relaciones concretas con el tiempo histórico presente de la Argentina. De esta manera, el correlato entre ficción y realidad daba lugar al reconocimiento de situaciones que conmovían a la sociedad, y con este reconocimiento, la posibilidad de hacerlas visibles y plausibles de ser cuestionadas. La Razón del 31 de julio de 1981 titulaba su crítica de Tiempo de revancha "Audaz Alegoría en un atrayente Filme” para luego especificarla como el "enfrentamiento de un individuo y las organizaciones que abusan del poder al amparo de ciertas circunstancias”, haciendo alusión a la convivencia de la empresa constructora para la que éste trabajaba y el poder político de la dictadura. 35 Por su parte, para referirse al siguiente filme de Aristarain, Últimos días de la víctima, la crónica publicada en La Nación del 9 de abril de 1982 se concentraba en el accionar de Mendizábal, el frío asesino a sueldo que no manifestaba remordimientos en el momento de torturar y matar a sus víctimas. Asimismo cruzaba el personaje y su historia con los datos de la puesta en escena haciendo referencia a los espacios de la ciudad de Buenos Aires por los que el asesino transitaba ("desde departamentos en pisos torre hasta casuchas perdidas al borde de las rutas, desde ominosas oficinas donde le encargan sus trabajos, hasta hoteles de mala muerte”), construyendo de esa manera un entorno en el que la corrupción política y económica encontraba en la figura de Mendizábal un

34Andrés, Alfredo, "El ser humano enfrentado a los abismos de sus últimos temores", La opinión, 21 de agosto de 1980.

35 "Audaz Alegoría en un Atrayente Filme”, La Nación, 31 de julio de 1981. 
sujeto dual: el que reproduce el orden de cosas imperante y el que sin darse cuenta lo padece y lo paga con su propia vida. $3^{3}$

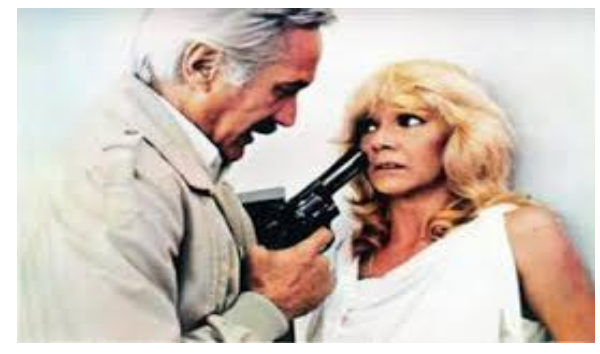

F7. Mendizábal, el asesino a sueldo de Últimos días de la víctima que amedrenta y tortura sin límites

En lo que concierne a los medios periodísticos alternativos, se generó un tercer criterio argumentativo que, partiendo de los filmes, ejercía la crítica polémica al accionar de la dictadura. Como ha expresado Mariana Cerviño, frente a un espacio público prácticamente extinguido, las revistas que funcionaban subterráneamente se vuelven lugares de encuentro: "A través de las crónicas que intervienen en la formación del gusto de los lectores, extienden visiones de mundo alternativas al clima opresivo que ha tomado la cultura masiva, más controlada por las políticas del Estado dictatorial" (Cerviño, 2012, p. 108). En el caso del cine, los periodistas no se contentaban únicamente con la posibilidad de desentrañar las matrices alegóricas y metafóricas a fines de probar la inclinación de los filmes a la resistencia y la crítica política, sino que se apropiaban de ellos para exponer ideas propias en torno a la coyuntura que atravesaba el país. Entre estos medios, la revista Humor, activa entre 1978 y 1999, y de la cual participaron como columnistas Aída Bortnik y José Pablo Feinmann -dos de los escritores que colaboraron en la redacción de los guiones de varios de los filmes de la tendencia cinematográfica analizada- combinaba el texto escrito con el humor gráfico y la caricatura, conformando verdaderas piezas satíricas que denunciaban el accionar de las autoridades militares. Como ejemplo, en la edición de septiembre de 1981, dedicada al estreno de Tiempo de revancha, más que centrarse en el análisis del filme (del cual destacaba las interpretaciones y la actitud alegórica de la historia de Pedro Bengoa, el obrero puesto a simular un accidente de trabajo para cobrar una gran suma de dinero), la nota se detiene en otros aspectos que permiten producir reflexiones más abarcadoras acerca del cine en tanto bien cultural y

${ }_{36}^{6}$ S/F, "Riguroso y despiadado, pero también el mejor filme de Adolfo Aristarain”, La Nación, 9 de abril de 1982. 
social. Haciendo referencia a la producción cinematográfica local de la época, el periodista enfrentaba el cine pasatista y de entretenimiento al cine adulto y de compromiso, enmarcando en estas dos últimas denominaciones el filme de Aristarain. En tanto, la nota se acompañaba de dos piezas de humor gráfico que funcionaban fijando y potenciando la palabra escrita. En una de ellas se contrastaba el filme Las señoritas de Wilco (Andrej Wajda, 1979) -visto en la fecha por un segmento del público argentino- con la figura de Camila Perissé (actriz y vedette argentina que en ese momento participaba en la obra teatral $L a$ señorita de Tacna y, de igual manera, en programas televisivos y filmes que convocaban a sectores populares de espectadores), visualizando mediante el ejercicio de la comparación y la parodia la convivencia en el espectro cultural de formas artísticas disidentes e incluso el horizonte de expectativas del espectador medio. ${ }^{37}$ En la segunda pieza gráfica, por su parte, se hacía referencia a los hechos de coerción y vandalismo político (las amenazas de bomba) que sufrieron algunas salas de exhibición en esos años oscuros, entre ellas el cine Ambassador al momento del estreno de este filme de Aristarain. ${ }^{38}$

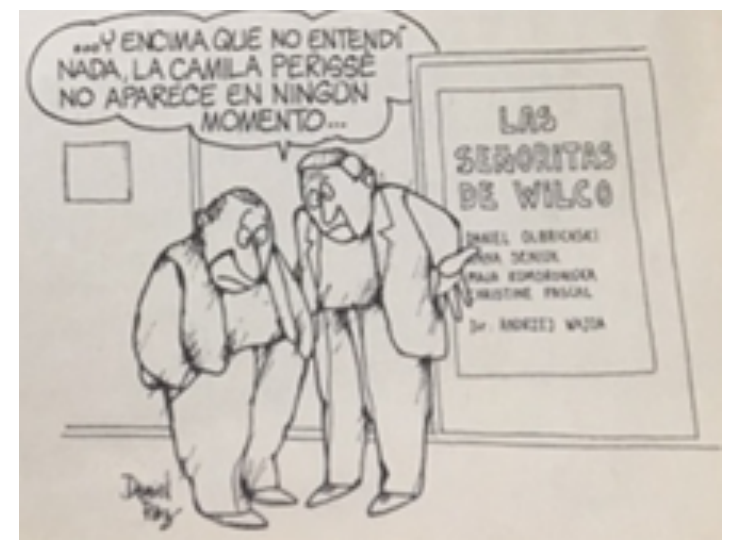

F8. Pieza gráfica que acompañaba el comentario de Tiempo de revancha, revista Humor

37 El nombre de Camila Perissé, mencionado en la pieza gráfica, permite reparar en la complejidad del mundo cultural de la época. Se trata de una actriz que desarrolló una carrera sumamente versátil. En el campo del teatro, entre otros espectáculos, participó del estreno mundial de $L a$ señorita de Tacna de Mario Vargas Llosa, ocurrido en 1981 en el teatro Blanca Podestá, con dirección de Emilio Alfaro y participación protagónica de Norma Aleandro. Simultáneamente, encabezó numerosas comedias eróticas y picarescas, transformándose en una actriz aclamada por el público masculino. En 1981, junto con su actuación en teatro, se la pudo ver en pantalla en los filmes Te rompo el rating (Hugo Sofovich), La pulga en la oreja (Pancho Guerrero) y Abierto día y noche (Fernando Ayala).

38 "Cine Argentino 1981: A la manera de una gran semilla", Humor, septiembre de 1981, No 65. 


\section{Consideraciones finales}

Es mi intención concluir el análisis enfatizando el lugar destacado y trascendente ocupado por las ficciones hermético-metafóricas en los años de la última dictadura militar argentina. Los filmes aportaron un paradigma estéticoideológico innovador, al articular los códigos propios de las operaciones alegóricas y metafóricas con una intencionalidad crítica y reflexiva concreta sobre el tiempo histórico presente. A su vez, movilizaron un amplio conjunto de voluntades que, como se ha procurado exponer, incluyeron a los equipos de trabajo, a quienes comercializaron y exhibieron los filmes, a un segmento nada despreciable de espectadores y a la prensa gráfica en sus distintas vertientes. El empeño de todos ellos en promover esta línea cinematográfica ha radicado en múltiples factores: comerciales, artísticos, o bien en la intención de fijar un posicionamiento intelectual a favor de la reflexión, la crítica y la resistencia a la política dictatorial. En particular, en el último caso señalado, diferentes agentes de la sociedad conformaron y mantuvieron activo un tejido cultural que defendía la libertad de expresión y la perdurabilidad de la vida. En cuanto a los medios periodísticos, con las actitudes y formas discursivas anteriormente identificadas, se constituyeron en un factor relevante en la presencia efectiva de los filmes en el campo cultural y en la agenda de la opinión pública. Si bien algunos medios oficiaron como portavoces del régimen y, de igual manera daban voz y espacio a los realizadores y protagonistas de las películas, no fueron ajenos a los filmes y a las polémicas que estos ocasionaban.

Ya se ha mencionado que la época estudiada fue compleja y que estuvo revestida de múltiples y controversiales matices. $\mathrm{Al}$ respecto es necesario hacer referencia asimismo al hecho de que, más allá de lo analizado en torno a la circulación en salas locales, fueron muchos los filmes de la tendencia que tuvieron reconocimiento institucional y distinciones en festivales de Argentina y del mundo. Como ejemplo emblemático, La isla fue designada por el Instituto Nacional de Cinematografía -mismo organismo que había objetado algunos de los actores convocados- para representar a la Argentina en el Festival de Montreal de 1979. Simultáneamente, recibía un premio de la Oficina Católica Internacional del Cine y, en un breve lapso de tiempo, tres menciones en el Festival de Cine Iberoamericano de Huelva. Unos años más tarde, Tiempo de revancha, arrasaba en los festivales de Montreal, San Sebastián, La Habana, Cartagena y Biarritz, 
además de ser estrenada con éxito en Estados Unidos y Europa. Todos estos acontecimientos desvelan que fue este conjunto de ficciones herméticometafóricas el que abrió para el cine argentino de la época los mercados extranjeros y los espacios en los festivales, siendo la calidad artística y la dimensión semántica los factores que garantizaron estas posibilidades.

A partir de estos hechos, es presumible pensar que, en su tránsito hacia el exterior, las imágenes y sonidos asumieron otro tipo de resonancias. Al escenificar transversalmente los abusos de poder y el terror desencadenado por el gobierno militar, los filmes colaboraron en la difusión y la denuncia de estas situaciones más allá de las fronteras nacionales. Junto con los documentales realizados en el exilio por directores y colectivos perseguidos por el régimen militar y las campañas mundiales que delataban la violación de los derechos humanos, las ficciones alegórico-metafóricas se asociaron comprensiblemente a los propósitos de la resistencia y la denuncia. $39 \mathrm{Al}$ cuestionar los ideales y el canon realista-costumbrista promovidos desde el Instituto Nacional de Cinematografía, la factura textual de los filmes, opaca, compleja y sofisticada, demostraba que había algo más allá -y muy potente- gestándose en la Argentina en el plano artístico y cultural.

\section{Referencias bibliográficas}

Avellaneda, A. (1896). Censura, autoritarismo y cultura: Argentina 1960-1983. Buenos Aires: Centro Editor de América Latina.

Brenner, F. (1993). Adolfo Aristarain. Los directores del cine argentino. Buenos Aires: Centro Editor de América Latina.

Campo, J. (2015). With the Southern Cross at their backs. Documentary Film from the Southern Cone during Exile (1970-1980). Latinoamérica: The Time and the People: Memories, Passion, Work and Life (pp. 4-10): Yamagata: Yamagata International Documentary Film Festival.

Campo, J. (2017). Revolución y Democracia - El cine documental argentino del exilio 1976/1984. Buenos Aires: Fundación CICCUS.

Cerviño, M. E. (2012). Las revistas culturales como espacios de resistencia en la última dictadura militar argentina. De El Expreso Imaginario a El Porteño. Desafios (24), 105-134. http://www.redalyc.org/articulo.oa?id=359633172005.

39 Estas formas audiovisuales actuaron como punta de lanza respecto de los filmes realizados luego del retorno de la democracia en 1983, en los que existió como sostuvo Marcela Visconti (2014) una clara actitud de denuncia manifiesta. 
Gociol, J. \& Invernizzi, H. (2006), Cine y dictadura. La censura al desnudo. Buenos Aires: Capital Intelectual.

Lusnich, A. L. (2015). Resistencia política y ficción cinematográfica: Argentina 1976-1989, Significação - Revista de Cultura Audiovisual 42(43), 96-113. DOI: https://doi.org/10.11606/issn.2316-7114.sig.2015.98294.

Lusnich A. L. (2016). Formas del disciplinamiento social en las ficciones alegóricas y metafóricas realizadas en épocas de la dictadura y la postdictadura en Argentina. IdeAs. Idées d'Amérique (7), 1-17. http://journals.openedition.org/ideas/1528; DOI: 10.4000/ideas.1528.

Pellettieri, O. (1994). Teatro argentino contemporáneo (1980-1990). Buenos Aires: Editorial Galerna.

Rodríguez, L. (2015). Cultura y dictadura en Argentina (1976-1983). Estado, funcionarios y políticas. Anuario Colombiano de Historia Social y de la $\begin{array}{llll}\text { Cultura } & 42 & \text { (2), }\end{array}$ DOI: https://doi.org/10.15446/achsc.v42n2.53338.

Romano, S. (2007). Detrás de la pantalla: autoritarismo, censura y represión en los medios: Un estudio de caso, Córdoba 1973-1983, Prohistoria [online] (11), 61-89 http://www.scielo.org.ar/scielo.php?script=sci arttext\&pid=S1851$\mathrm{pp}$. 95042007000100004.

Sorlin, P. (2013). Prefacio. En R. Muller \& T. Wieder (Dir.), Cine y regímenes autoritarios del siglo $X X$ (pp. 9-20). Buenos Aires: Nueva Visión.

Visconti, M. (2014). Lo pensable de una época. Sobre La historia oficial de Luis Puenzo. Aletheia. 4 (8) 1-13. http://www.aletheia.fahce.unlp.edu.ar/numeros/numeros/numero8/articulos/lo-pensable-de-una-epoca.-sobre-la-historia-oficial-de-luispuenzo

Weinritcher, A. (2005). Jugando en los archivos de lo real. Apropiación y remontaje en el cine de no ficción. En C. Torreiro \& J. Cerdan (Eds), Documental y vanguardia (pp. 43-64). Madrid, España: Cátedra.

Wolf, S. (1992). El cine del Proceso. Estética de la muerte. Cine argentino: la otra historia, Buenos Aires: Letra Buena.

Xavier, I. (1999). Historical Allegories. En T. Miller \& (Eds.), A companion to filme theory. Oxford, Inglaterra, Blackwell. 